\title{
Standardized Library of Asthma Outcome Measures
}
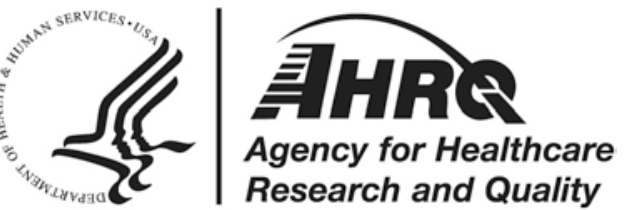


\section{Research White Paper}

\section{Standardized Library of Asthma Outcome Measures}

\section{Prepared for:}

Agency for Healthcare Research and Quality

Center for Outcomes and Evidence

5600 Fishers Lane

Rockville, MD 20857

www.ahrq.gov

Contract No. 290-2014-00004-C

Prepared by:

L\&M Policy Research, LLC

Washington, DC 20009

With partners: OM1, AcademyHealth

\section{Investigators:}

Richard E. Gliklich, $\mathrm{MD}^{1}$

Michelle B. Leavy, $\mathrm{MPH}^{1}$

Fang Li, MD, MS ${ }^{1}$

${ }^{1} \mathrm{OM} 1$

AHRQ Publication No. 19-EHC004-EF

April 2019 
This report is based on research conducted by the Agency for Healthcare Research and Quality (AHRQ) Evidence-based Practice Centers' Methods Workgroup. The findings and conclusions in this document are those of the authors, who are responsible for its contents; the findings and conclusions do not necessarily represent the views of AHRQ. Therefore, no statement in this report should be construed as an official position of AHRQ or of the U.S. Department of Health and Human Services.

\section{None of the investigators have any affiliations or financial involvement that conflicts with the material presented in this report.}

The information in this report is intended to help EPCs and AHRQ understand health-systems need and use of evidence to inform their decisionmaking. This report is not intended to be a substitute for the application of clinical judgment. Anyone who makes decisions concerning the provision of clinical care should consider this report in the same way as any medical reference and in conjunction with all other pertinent information, i.e., in the context of available resources and circumstances presented by individual patients.

This report is made available to the public under the terms of a licensing agreement between the authors and the Agency for Healthcare Research and Quality. This report may be used and reprinted without permission except those copyrighted materials that are clearly noted in the report. Further reproduction of those copyrighted materials is prohibited without the express permission of copyright holders.

AHRQ or U.S. Department of Health and Human Services endorsement of any derivative products that may be developed from this report, such as clinical practice guidelines, other quality enhancement tools, or reimbursement or coverage policies, may not be stated or implied.

Persons using assistive technology may not be able to fully access information in this report. For assistance contact epc@ahrq.hhs.gov.

Suggested citation: Gliklich RE, Leavy MB, Li F. Standardized Library of Asthma Outcome Measures. Research White Paper. (Prepared by L\&M Policy Research, LLC under Contract No. 290-2014-00004-C.) AHRQ Publication No. 19-EHC004-EF. Rockville, MD: Agency for Healthcare Research and Quality; April 2019. Posted final reports are located on the Effective Health Care Program search page.

DOI: https://doi.org/10.23970/AHRQEPCLIBRARYASTHMA. 


\section{Preface}

The Agency for Healthcare Research and Quality (AHRQ), through its Evidence-based Practice Centers (EPCs), sponsors the development of evidence reports and technology assessments to assist public- and private-sector organizations in their efforts to improve the quality of health care in the United States.

The reports and assessments provide organizations with comprehensive, science-based information on common, costly medical conditions and new health care technologies and strategies. The EPCs systematically review the relevant scientific literature on topics assigned to them by AHRQ and conduct additional analyses when appropriate prior to developing their reports and assessments.

To improve the scientific rigor of these evidence reports, AHRQ supports empiric research by the EPCs to help understand or improve complex methodologic issues in systematic reviews. These methods research projects are intended to contribute to the research base in and be used to improve the science of systematic reviews. They are not intended to be guidance to the EPC program, although may be considered by EPCs along with other scientific research when determining EPC program methods guidance.

AHRQ expects that the EPC evidence reports and technology assessments will inform individual health plans, providers, and purchasers as well as the health care system as a whole by providing important information to help improve health care quality. The reports undergo peer review prior to their release as a final report.

If you have comments on this Methods Research Project they may be sent by mail to the Task Order Officer named below at: Agency for Healthcare Research and Quality, 5600 Fishers Lane, Rockville, MD 20857, or by email to epc@ahrq.hhs.gov.

Gopal Khanna, M.B.A

Director

Agency for Healthcare Research and Quality Improvement

Stephanie Chang, M.D., M.P.H.

Director

Evidence-based Practice Center Program

Center for Evidence and Practice Improvement Agency for Healthcare Research and Quality
Arlene Bierman, M.D., M.S.

Director

Center for Evidence and Practice

Agency for Healthcare Research and Quality

Elise Berliner, Ph.D.

Task Order Officer

Center for Evidence and Practice

Improvement

Agency for Healthcare Research and Quality 


\section{Contents}

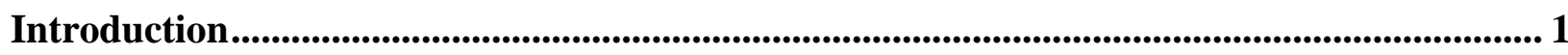

Approach to Representing an Outcome Definition............................................................... 2

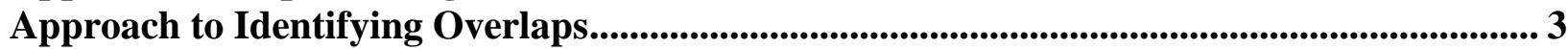

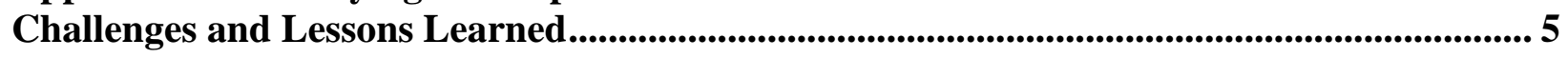

\section{Appendixes}

Appendix A. Harmonized Definitions for Asthma Outcome Measures Appendix B.

Standardized Library of Asthma Outcome Measures (posted separately) 


\section{Introduction}

Significant variation exists in both the types and definitions of outcome measures used in patient registries, even within the same clinical area. This variation reduces the utility of registries, making it difficult to compare, link, and aggregate data across the spectrum of clinical care and reporting. To address these limitations, the Agency for Healthcare Research and Quality (AHRQ) developed the Outcome Measures Framework (OMF), a conceptual model for classifying outcomes that are relevant to patients and providers across most conditions; it is intended to serve as a content model for developing harmonized outcome measures for specific clinical areas. $^{\text {a }}$

AHRQ is assessing the feasibility of using the OMF to develop standardized libraries of outcome measures in five clinical areas, including (1) Atrial fibrillation, (2) Asthma, (3) Depression, (4) Lung cancer, and (5) Lumbar spondylolisthesis. ${ }^{b}$ These clinical areas represent diverse populations and care settings, different treatment modalities, and varying levels of harmonization. For each clinical area, the relevant registries and observational studies are identified, and registry sponsors, informaticists, and clinical subject matter experts are invited to participate in a registry group that focuses on harmonizing outcome measures through a series of in-person and web-based meetings. A stakeholder group, including payers, patient representatives, Federal partners and health system leaders, is also assembled to discuss challenges and provide feedback on the harmonization effort.

A key goal of this effort is to standardize the definitions of the components that make up the outcome measures, so users can understand the level of comparability between measures across different systems and studies. As a final step in the harmonization process, clinical informaticists map the narrative definitions (generated by the workgroups) to standardized terminologies to produce a library of common data definitions.

This document describes the technical approach used to prepare the Standardized Library of Asthma Outcome Measures workbook. For reference, the narrative definitions for the minimum set of outcome measures produced by the Asthma Workgroup are included in Appendix A.

\footnotetext{
${ }^{a}$ Gliklich RE, Leavy MB, Karl J, et al. A framework for creating standardized outcome measures for patient registries. Journal of Comparative Effectiveness Research. 2014;3(5):473-80.

${ }^{b}$ This work was supported by the Office of the Secretary Patient-Centered Outcomes Research Trust Fund under Interagency Agreement \#16-566R-16.
} 


\section{Approach to Representing an Outcome Definition}

For each measure, the accompanying workbook (Appendix B) contains the narrative definition and recommended reporting period (timeframe), the initial population for measurement (e.g., all asthma patients, all asthma patients ages 12 and older), the outcome focused population (patients who experienced the outcome of interest), and the data criteria and value sets.

Electronic Health Record (EHR) data often will not contain all the requisite components of an outcome definition that would allow for the computational confirmation of that outcome. The approach used for this project is to gather the clinician's assertion of an outcome condition and as much supporting evidence as possible, so that even where the expression logic cannot computationally confirm an outcome, some structured evidence might still be available.

Relationships between events raise a challenge because relationships are often not directly asserted in an EHR. Thus, where possible, relationships have been inferred based on time stamps and intervals. Where this is not possible (e.g., cause of death), the logic requires an asserted relationship.

For each outcome, the following have been defined:

- An object representing the outcome condition itself: In many cases, the only structured data will be an assertion of an outcome, with all the supporting evidence being present in the narrative.

- Fast Healthcare Interoperability Resources (FHIR) for evidence for the outcome: These include labs, diagnostic imaging, etc.

- FHIR for additional relevant events: These might include procedures, encounters, etc.

- Temporal aspects for all events: These allow for inferred relationships. 


\section{Approach to Identifying Overlaps}

A key goal of this project is to leverage existing resources and build connections across initiatives, where possible. To support that goal, the following sources were searched for overlap:

- https://ecqi.healthit.gov/: Primarily looking for overlapping criteria

- https://vsac.nlm.nih.gov/: Primarily looking for overlapping value sets

- C-CDA: Primarily looking for overlapping data representations

- https://www.nlm.nih.gov/cde/: Primarily looking for overlapping data element definitions

Each website has a specific, unique purpose, and data representations vary, so while there are some direct comparisons with similar use cases, there are also important differences both in terms of data structures and use cases. Results of the comparisons are provided below.

- https://ecqi.healthit.gov/; https://vsac.nlm.nih.gov/:

o Asthma-related value sets in VSAC:

- There are 3 Asthma Condition value sets and 1 Asthma Medication value set in VSAC:

- Asthma (Joint Commission, 91 codes)

2.16.840.1.113883.3.117.1.7.1.271

- Asthma (PCPI Foundation, 83 codes)

2.16.840.1.113883.3.526.3.362

- Asthma Diagnosis Grouping (AAAAI, 104 codes)

2.16.840.1.113762.1.4.1047.309

- Preferred Asthma Therapy (NCQA, 105 codes) 16.840.1.113883.3.464.1003.196.12.1212

- Reasons for differences include:

- Different use cases.

- $\quad$ /- inclusion of retired codes.

- Different groups find different codes.

- Drug class ambiguities.

- $\quad$ /- inclusion on non-billable ICD codes.

- Lack of intensional rules makes comparison difficult.

o eCQMs are based on the National Quality Forum's Quality Data Model, as expressed as HL7 QRDA templates, whereas this project is based on FHIR version 1.8.0 objects. ${ }^{\mathrm{C}}$ The HL7 Clinical Quality Improvement committee is actively harmonizing QDM and FHIR resources, and a FHIR-based quality reporting format is expected to be balloted soon.

\footnotetext{
c http://hl7.org/fhir/2017Jan/index.html
} 
o VSAC does not at this time provide intensionally-defined value sets. Therefore, comparisons are done based on enumerated lists.

- C-CDA:

o There are no asthma-specific templates or value sets in C-CDA.

- $\quad$ https://www.nlm.nih.gov/cde/:

o We were unable to identify any data elements that laid out specific criteria for any of the asthma outcomes. CDEs generally look for presence/absence of a condition, and may associate a condition with a code system or value set. As a result, there was minimal overlap between any asthma outcome and existing CDEs. 


\section{Challenges and Lessons Learned}

Some challenges were encountered in translating the text definitions produced by the workgroup into standardized definitions and value sets. Of note, several outcome measures focus on change over time, such as change in medication dosage or change in pulmonary function over a 12-month period. These measures require multiple measurements in the data representations. The workgroup recommended using the first and last measurement within the parameter of "interval of interest" (generally 12 months). For these measures, narrative representations of the changes rather than detailed programming logic are provided.

Related to the outcomes occurring outside of the clinical setting or patient reported activities (e.g., missed work/school days, asthma-related quality of life, medication adherence), condition specific instruments and/or standard terminology representing the instruments may not exist.

Lastly, the workgroup recommended measuring days of work or school missed due to asthma. While missed work or school days may be captured within the EHR setting, there is no reliable way to assert that the missed days are due to asthma (as opposed to another condition).

The project team will apply these lessons learned in subsequent workgroups. 


\section{Appendix A. Harmonized Definitions for Asthma Outcome Measures}

\begin{tabular}{|l|c|c|}
\hline $\begin{array}{l}\text { OMF } \\
\text { CATEGORY }\end{array}$ & $\begin{array}{c}\text { OUTCOME } \\
\text { MEASURE }\end{array}$ & DEFINITION \\
\hline Survival & Death (asthma-related) & Death due to asthma, reported in 12-month intervals. \\
\hline Clinical Response & Exacerbation & $\begin{array}{c}\text { Exacerbations of asthma are episodes characterized by an } \\
\text { increase in symptoms of shortness of breath, cough, wheezing or } \\
\text { chest tightness and decrease in lung function, i.e. they represent a } \\
\text { change from the patient's usual status that is sufficient to require a } \\
\text { change in treatment. Exacerbation includes any of the following: } \\
\text { Prescribed systemic steroids (defined as 2 or more days of oral } \\
\text { steroids or a steroid injection) or increasing the oral steroid dose } \\
\text { from dose at baseline. }\end{array}$ \\
& $\begin{array}{c}\text { An asthma-related hospitalization, ED visit, urgent care center visit, } \\
\text { or unscheduled office visit requiring prescription of systemic } \\
\text { corticosteroids. } \\
\text { Documentation by provider of acute asthma exacerbation. }\end{array}$ \\
\hline
\end{tabular}




\begin{tabular}{|c|c|c|c|}
\hline $\begin{array}{c}\text { OMF } \\
\text { CATEGORY }\end{array}$ & $\begin{array}{l}\text { OUTCOME } \\
\text { MEASURE }\end{array}$ & DEFINITION & MEASUREMENT NOTES \\
\hline Clinical Response & $\begin{array}{l}\text { Change in asthma control } \\
\text { (adults - ages } 12 \text { and } \\
\text { older) }\end{array}$ & $\begin{array}{c}\text { Measurement Tools } \\
\text { ACT } \\
\text { Not well-controlled: } \leq 19 \\
\text { MID: Increase in score } \geq 3 \text { points } \\
\text { ACQ } \\
\text { Not well-controlled: } \geq 1.5 \\
\text { MID: Decrease in score } \geq .5 \text { points } \\
\text { ATAQ } \\
\text { Not well-controlled: } \geq 1 \\
\text { MID: Decrease in score } \geq 1 \text { point } \\
\text { Improving in Asthma Control: } \\
\text { not well controlled to controlled OR change } \\
\text { control. } \\
\text { Change (MID) improvement in } \\
\text { representing minimal important difference } \\
\text { Woning in Asthma Control: } \\
\text { Change from controlled to not well controlled OR change } \\
\text { representing minimal important difference (MID) decrease in } \\
\text { control. } \\
\text { Stable Level of Asthma Control: } \\
\text { Patient remains stable throughout measurement period (controlled } \\
\text { or not well-controlled) OR does not demonstrate a change in score } \\
\text { representing the minimal important difference (MID). } \\
\text { Reported in 12-month intervals. }\end{array}$ & $\begin{array}{l}\text { Patient scores (as opposed } \\
\text { to 'controlled' vs. } \\
\text { 'uncontrolled' only) on the } \\
\text { selected measurement } \\
\text { instrument should be } \\
\text { recorded to permit future } \\
\text { analyses. } \\
\text { Where multiple } \\
\text { measurements are } \\
\text { available, the first and last } \\
\text { measurement in the 12- } \\
\text { month measurement period } \\
\text { should be used. }\end{array}$ \\
\hline
\end{tabular}




\begin{tabular}{|c|c|c|c|}
\hline $\begin{array}{c}\text { OMF } \\
\text { CATEGORY }\end{array}$ & $\begin{array}{l}\text { OUTCOME } \\
\text { MEASURE }\end{array}$ & DEFINITION & MEASUREMENT NOTES \\
\hline Clinical Response & $\begin{array}{l}\text { Change in asthma control } \\
\text { (pediatrics - under age 12) }\end{array}$ & 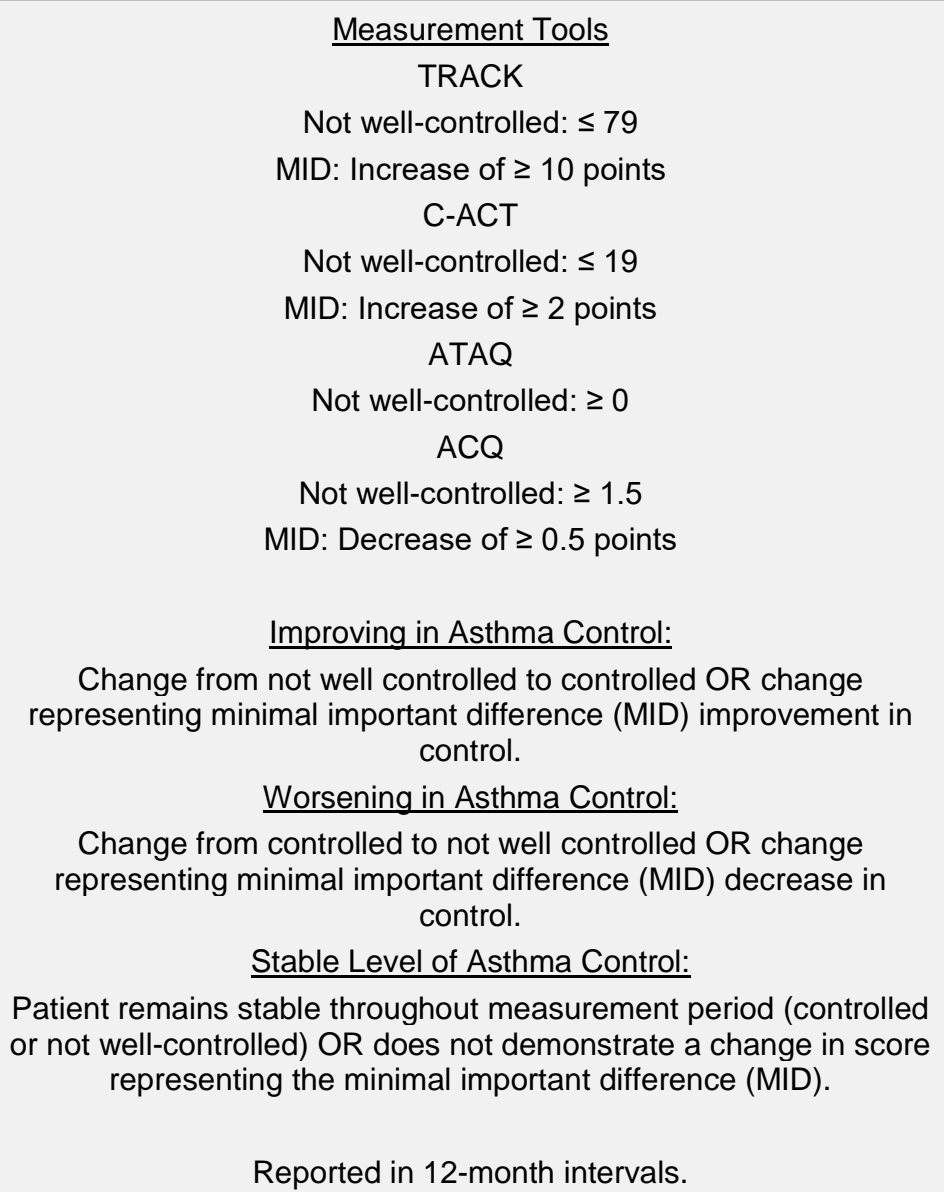 & $\begin{array}{l}\text { Patient scores (as opposed } \\
\text { to 'controlled' vs. } \\
\text { 'uncontrolled' only) on the } \\
\text { selected measurement } \\
\text { instrument should be } \\
\text { recorded to permit future } \\
\text { analyses. } \\
\text { Where multiple } \\
\text { measurements are } \\
\text { available, the first and last } \\
\text { measurement in the 12- } \\
\text { month measurement period } \\
\text { should be used. }\end{array}$ \\
\hline
\end{tabular}




\begin{tabular}{|c|c|c|c|}
\hline $\begin{array}{l}\text { OMF } \\
\text { CATEGORY }\end{array}$ & $\begin{array}{l}\text { OUTCOME } \\
\text { MEASURE }\end{array}$ & DEFINITION & MEASUREMENT NOTES \\
\hline Clinical Response & $\begin{array}{l}\text { Pre-bronchodilator Indices } \\
\text { (Pre-bronchodilator } \\
\text { FEV1\% \& FVC\% \& } \\
\text { FEV1/FVC ratio) }\end{array}$ & $\begin{array}{l}\text { Change in measurements over } 12 \text {-month period. } \\
\text { The goal is to have } 2 \text { measurements in } 12 \text {-month period. Two } \\
\text { measurements within a } 24 \text {-month period is also acceptable, if two } \\
\text { measurements within } 12 \text { months are not available. }\end{array}$ & $\begin{array}{l}\text { Recommended for patients } \\
\text { ages } 5 \text { and above. } \\
\text { Use first and last } \\
\text { measurement if more than } 2 \\
\text { measurements are } \\
\text { available in 12-month } \\
\text { period. }\end{array}$ \\
\hline Clinical Response & $\begin{array}{l}\text { Change in asthma } \\
\text { controller medication use }\end{array}$ & $\begin{array}{l}\text { Measured by patient/caregiver self-report, physician report, } \\
\text { prescription fill, or electronic monitoring. } \\
\text { Preferred asthma controller medications are inhaled } \\
\text { corticosteroids. While long-acting bronchodilators alone are not, } \\
\text { combination inhaled corticosteroid and long-acting bronchodilator } \\
\text { medications are considered controller medications. Additional } \\
\text { controller medications include leukotriene modifiers, long-acting } \\
\text { muscarinic antagonists, and immunomodulators. }\end{array}$ & \\
\hline Clinical Response & $\begin{array}{l}\text { Change in quick-relief } \\
\text { asthma medication use }\end{array}$ & $\begin{array}{l}\text { Measured by patient/caregiver self-report, physician report, } \\
\text { prescription fill, or electronic monitoring. } \\
\text { Preferred asthma quick-relief medications are short-acting beta- } \\
\text { agonists (SABAs), e.g., albuterol. An additional quick-relief } \\
\text { medication includes ipratropium bromide. }\end{array}$ & \\
\hline Events of Interest & $\begin{array}{l}\text { Systemic corticosteroids } \\
\text { for asthma }\end{array}$ & $\begin{array}{l}\text { Defined as a prescription for systemic steroids filled within } 7 \text { days } \\
\text { of a healthcare visit for asthma (i.e., with an ICD-10 code } \\
\text { associated with asthma). Counted as number of events per patient } \\
\text { in a 12-month reporting period. }\end{array}$ & \\
\hline Events of Interest & Asthma-specific ED visits & $\begin{array}{l}\text { Defined as the number of ED visits per patient in the 12-month } \\
\text { reporting period. }\end{array}$ & \\
\hline Events of Interest & $\begin{array}{l}\text { Asthma-specific hospital } \\
\text { admission }\end{array}$ & $\begin{array}{c}\text { Defined as the number of hospital admissions due to asthma per } \\
\text { patient in the 12-month reporting period. }\end{array}$ & \\
\hline
\end{tabular}




\begin{tabular}{|c|c|c|c|}
\hline $\begin{array}{l}\text { OMF } \\
\text { CATEGORY }\end{array}$ & $\begin{array}{l}\text { OUTCOME } \\
\text { MEASURE }\end{array}$ & DEFINITION & MEASUREMENT NOTES \\
\hline Events of Interest & Near fatal asthma & 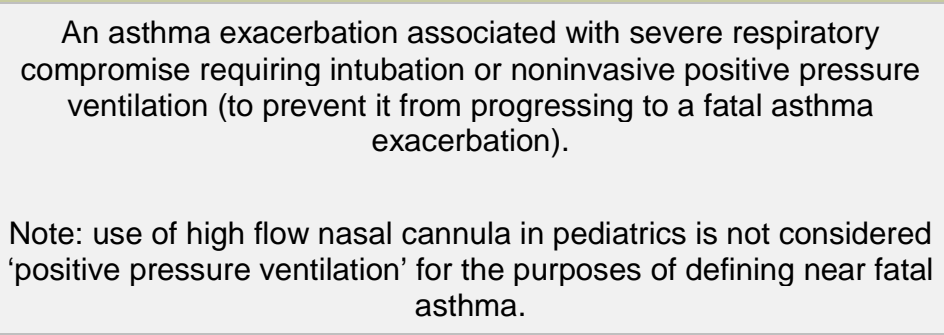 & \\
\hline Events of Interest & $\begin{array}{l}\text { Medication adverse } \\
\text { events }\end{array}$ & Adverse events related to asthma medications. & \\
\hline Patient Reported & Asthma control & $\begin{array}{l}\text { Patient who had a diagnosis of asthma and whose asthma was } \\
\text { optimally controlled during the measurement period as defined by } \\
\text { achieving BOTH of the following: } \\
\text { Asthma well-controlled as defined by the most recent asthma } \\
\text { control tool result available during the measurement period, and } \\
\text { Patient not at elevated risk of exacerbation as defined by fewer } \\
\text { than two emergency department visits and/or hospitalizations due } \\
\text { to asthma in the last } 12 \text { months. }\end{array}$ & \\
\hline Patient Reported & Medication adherence & $\begin{array}{l}\text { Measured by patient/caregiver self-report, physician report, } \\
\text { prescription fill, or electronic monitoring. }\end{array}$ & \\
\hline Patient Reported & $\begin{array}{l}\text { Asthma-specific quality of } \\
\text { life }\end{array}$ & $\begin{array}{c}\text { Asthma-specific quality of life should be measured using a brief, } \\
\text { validated, publicly available instrument that is appropriate for the } \\
\text { population of interest. }\end{array}$ & \\
\hline Patient Reported & General quality of life & $\begin{array}{l}\text { General quality of life should be measured using a quality of life } \\
\text { instrument that is validated and commonly used (e.g., PROMIS } \\
\text { Global 10, VR-12). }\end{array}$ & \\
\hline
\end{tabular}




\begin{tabular}{|c|c|c|c|}
\hline $\begin{array}{l}\text { OMF } \\
\text { CATEGORY }\end{array}$ & $\begin{array}{l}\text { OUTCOME } \\
\text { MEASURE }\end{array}$ & DEFINITION & MEASUREMENT NOTES \\
\hline $\begin{array}{l}\text { Resource } \\
\text { Utilization }\end{array}$ & $\begin{array}{l}\text { Missed school } \\
\text { days/missed work days }\end{array}$ & 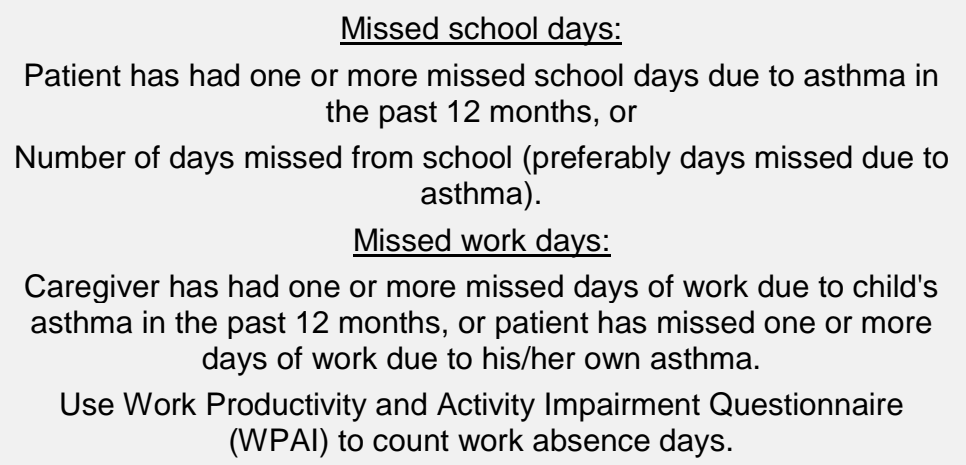 & \\
\hline $\begin{array}{l}\text { Resource } \\
\text { Utilization }\end{array}$ & Asthma medication ratio & $\begin{array}{l}\text { Calculated as the number of canisters of asthma controller } \\
\text { medication dispensed during the measurement year divided by the } \\
\text { number of canisters of total asthma medications dispensed } \\
\text { (controllers plus relievers) during the measurement year. }\end{array}$ & \\
\hline $\begin{array}{l}\text { Resource } \\
\text { Utilization/Events } \\
\text { of Interest }\end{array}$ & $\begin{array}{l}\text { Unscheduled visits to } \\
\text { primary care physician/ } \\
\text { visits to urgent care } \\
\text { center/ED visits/hospital } \\
\text { admission for asthma }\end{array}$ & $\begin{array}{l}\text { Unscheduled visits to primary care physician/visits to urgent care } \\
\text { center/ED visits/hospital admission for asthma, counted as number } \\
\text { of visits per patient in the 12-month reporting period. }\end{array}$ & \\
\hline $\begin{array}{l}\text { Resource } \\
\text { Utilization }\end{array}$ & $\begin{array}{l}\text { Treatment-related } \\
\text { resource utilization }\end{array}$ & $\begin{array}{l}\text { All resource utilization (as measured by cost) related to treatment } \\
\text { or management of asthma, including hospitalizations, ED visits, } \\
\text { urgent care center visits, office visits, medications, and other costs. }\end{array}$ & \\
\hline Experience of care & $\begin{array}{l}\text { Patient satisfaction with } \\
\text { care }\end{array}$ & $\begin{array}{l}\text { Patients with high care satisfaction, as measured by a brief, } \\
\text { validated, publicly available instrument. }\end{array}$ & \\
\hline
\end{tabular}

